\title{
Foreword-Special Issue: Codes, Cryptology and Curves in honour of Ruud Pellikaan
}

\author{
Peter Beelen ${ }^{1} \cdot$ Olav Geil ${ }^{2} \cdot$ Edgar Martínez-Moro $^{3} \cdot$ Xin-Wen $\mathbf{W u}^{4}$
}

Published online: 4 July 2020

(c) Springer Science+Business Media, LLC, part of Springer Nature 2020

We are proud to present this special issue in honor of Ruud Pellikaan. It presents 11 selected papers out of 27 submitted by the participants as postconference contributions of the workshop entitled "Codes, Cryptology and Curves in honour of Ruud Pellikaan" that took place at Eindhoven University of Technology (TU/e) 7-9 March of 2019. The workshop aimed to bring together researchers at all levels and career stages, providing an opportunity to share and discuss recent progress to celebrate Ruud's vast contribution to the fields of Coding Theory, Cryptology and Curves (Algebraic Geometry). There was a warm and supportive atmosphere during the meeting which showed the high esteem in which Ruud is held in the international mathematical community. As it is impossible to adequately cover all of the recent advances based on Ruud's works in a single issue, we intend to present a fragment of the timely research topics and noteworthy new developments related to his research. As we mentioned before, we received many more papers than we could include and we thank the authors of all the papers submitted. Due to the high quality of submissions, the process of deciding which papers to include was not easy and we are very grateful to the referees for their assistance in helping us reach our final selection. We also highly appreciate the journal and Springer Nature support during the entire process, specially the helpful support of Shamima Banu Rajesh who was available to us all the time.

We, Ruud's friends, colleagues, co-authors and students, have been privileged to benefit from his inspiration, hard work, dedication and generosity to his friends, and his contributions

Edgar Martínez-Moro

edgar.martinez@uva.es

Peter Beelen

pabe@dtu.dk

Olav Geil

olav@math.aau.dk

Xin-Wen Wu

xwu@iup.edu

1 Department of Applied Mathematics and Computer Science, Technical University of Denmark, Lyngby, Denmark

2 Department of Mathematical Sciences, Aalborg University, Aalborg, Denmark

3 Mathematics Research Institute (IMUVa), University of Valladolid, Valladolid, Spain

4 Department of Mathematical and Computer Sciences, Indiana University of Pennsylvania, Indiana, USA 
to mathematics. We are all looking forward to him really enjoying this special issue in his honor.

Publisher's Note Springer Nature remains neutral with regard to jurisdictional claims in published maps and institutional affiliations. 